\title{
INTRODUCTION TO GIORGI'S EXISTENTIAL PHENOMENOLOGICAL RESEARCH METHOD ${ }^{1}$
}

\section{INTRODUÇÃO AO MÉTODO DE PESQUISA FENOMENOLÓGICA EXISTENCIAL DE GIORGI}

\author{
Alberto De Castro ${ }^{2}$
}

\begin{abstract}
This article offers a brief introduction to the theoretical bases on which Amededo Giorgi supports his research work with a phenomenological existential approach. In the same way, it shows the different steps followed by that author in order to analyze the collected data in a researeh.
\end{abstract}

Keywords: Phenomenological approach; Phenomenology; Qualitative research; Ideographic analysis.

Resumo: Este artigo oferece uma breve introdução às bases teórias sobre as quais Amededo Giorgi apóia seu trabalho de pesquisa com uma abordagem existencial fenomenológica. Da mesma forma, mostra os diferentes passos seguidos por esse autor, a fim de analisar os dados coletados em uma pesquisa.

Palavras-chave: Abordagem fenomenológica; Fenomenologia; Pesquisa Qualitativa; Análise Ideográfica.

If we want to understand what the Existential Phenomenological research is, we should first clarify some important concepts about the way we conceive science in our culture. Generally speaking, when we talk about science we associate it with objective truths and with rigid laboratory methods. This has also been the case in social sciences, such as psychology, which have borrowed the natural sciences method to apply it in the field of human experience.

As a consequence of this situation, instead of comprehending the meaning of human experience, psychology has adjusted human experiences to the method of natural sciences. Psychology has attended human beings as mere objects because it has been adapting human experiences to some quantitative and abstract methods, about which we can only know facts. In this way, the meaning of experience is ignored because the most important thing is to quantify that experience and to know if that experience is right $01^{\prime}$

\footnotetext{
${ }^{1}$ This article was already published in the journal Psicología desde el Caribe, de la Universidad del Norte, which gave its permission to publish it in this journal. The reference is: De Castro, A. Introduction to Giorgi's existential phenomenological research method. Psicología desde el Caribe, Puerto Colombia, s.v, n. 11, p. 45-56, 2003.

${ }^{2}$ Ph.D. in Psychology, Saybrook University. Psicólogo, Universidad del Norte. Docente y miembro del grupo de investigación del departamento de psicología, Universidad del Norte, Colombia. Email: amdecast@uninorte.edu.co
} 
wrong. Then, psychologists have not seen that the only thing that they have been doing is to project their own theories on to the subjects as a way to validate them. In the name of objectivity, there is a big divorce between the researcher and the subject under study. The final result is that the psychologist cannot approach and understand the meaning of the experience for the person who is living that experience. Von Eckartsberg says (1998, p. 4) "that psychologists as Giorgi and Strasser have suggested that if psychology really wants to understand human beings it should put aside the natural science model".

On the other hand, Existential Phenomenological approach in psychology claims to have a comprehension and understanding of the experience of the human being from the consciousness and standpoint of the human being who is having the experience. In order to do this, these Existential Phenomenological psychologists have said that it is necessary to have a very different method in social sciences, which tries to reveal the essential meaning of the phenomenon under study, instead of creating abstract theories about the same phenomenon. In this way, McCall (1983, p. 57) comments, "To ignore the phenomena of conscious life just as they are given in experience is to abnegate the ultimate source of all knowledge in favor of physicalistic dogma".

Thus, it is very necessary to clarify that this method goes from the concrete description of the experience of a given subject (who is seen as a co-researcher) to the interpretation of her/his experience, instead of making abstract explanations about the experience of the subject without following and understanding the description of her/his experience as it is given in her/his consciousness. The difference between these two points of view is that in the first case, the researcher only gives an interpretation after seeing and following the description of the experience, just as it appears in the consciousness of the coresearcher, which leads it to catch its meaning. As Von Eckartsberg comments (1998, p. 21) about it:

\footnotetext{
We go first from unarticulated living (experiaction) to a protocol or account. We create a "life-text" that renders the experiaction in narrative language, as story. This process generates our data. Second, we move from the protocol to explication and interpretation. Finally, we engage in the process of the communication of findings.
}

A very important point that we have to keep in mind is that by doing this kind of research we focus on grasping the whole meaning of the experience, instead of dividing it into parts without understanding the basic meaning structure, which gives sense to the whole experience. If we divide a given experience into parts before having understood how the person who lives that experience articulates it, we are going to talk about abstract 
concepts that do not have any sense for that person. In other words, we cannot grasp a sense of the whole of a given experience by separating the parts from the general context in which every part is based. If we were to do so, we would make artificial explanations about experiences because we would be approaching them from our own perspective, which would be divorced from the sense of the whole of the experience for the person who lives it.

Sokolowski (2000, p. 23 - 24) comments that "a whole can be called a concretum, which is something that exists as a specific individual, which, in tum, can also be experienced and approached in a concrete way". He also says that there are parts that he calls moments, which cannot exist and present themselves apart from the whole to which they belong, even though he says that we could think about these parts as independent from their context. However, we should keep in mind that when we think in this way, these parts are not concrete things, but only abstract objects. These parts that are being thought of abstractly can be called abstractum.

The important point is that we, as researchers, should always keep in mind that we should not separate a given experience fram the concrete meaning structure of the person, because in this way we would lose the meaning that the person is trying to affirm in her/his daily life. Sokolowski (2000, p. 25) comments, "there is always a danger that we will separate the inseparable, that we will make the abstractum into a concretum". If we do that, we would be attributing an abstract meaning to a concrete experience, and we would also be talking about experiences and categories that do not really exist in the daily life for the person who lives that experience. Here is where the subject or co- researcher is seen as a mere object, which is the mistake that we should avoid in psychology. McCall (1983, p. 57) says about it: "To Husserl, no matter how refined the measurement or how ingenious the experimental techniques employed by empirical psychology, all its efforts are meaningless without a clear grasp of what it is that is being measured and correlated in the first place".

In order to really catch the whole meaning and concrete structure of the coresearcher, Existential Phenomenological psychologists begin by asking the coresearcher for a description of her/his actual experiences. The goal is to comprehend human experience as it is actually lived in the daily life and not in an artificial environment. Von Eckartsberg (1998), among others, has shown that there are four general and required steps to do Existential Phenomenological research, which include: 1) The formulation of a question (in which the researcher delineates a focus of 
investigation), 2) The data-generating situation (in which co-researchers give a description of her/his experience), 3) The data-analysis (in which the researcher reads the data given by the co-researchers and reveal the meaning of her/his experience), and 4) The presentation of findings (the researcher presents the research results in public).

There are different ways to do the analysis of these descriptions given by coresearchers (Van Eckartsberg's third step: data-analysis). The best known are the ones given by Adrian Van Kaam, Paul Colaizzi and Amedeo Giorgi, as Polkinghorne (1989) shows in his article "Phenomenological Research Methods". In addition, Von Eckartsberg (1998) also adds the models given by William Fischer and himself. Here, I will talk about the steps that Giorgi gives for doing a protocol analysis with an Existential Phenomenological approach: division into meaning units, meaning unit analysis or transformations, situated structure statement, and general structure statement.

Now, before talking about these steps, I would like to darify the context in which Giorgi is based. He situates himself within the perspective of the French Existential Phenomenological philosophers Merleau Ponty, who thinks that phenomenology is best understood in the light of the phenomenological method, which he says has four principal characteristics: it is descriptive, it uses the reduction, it searches for essences, and it is focused on the intentionality. Giorgi takes these characteristics as the basis of his work and method (GIORGI, 1985).

The first characteristic refers to the idea that the analysis and interpretation has to follow the concrete and naive description given by the co-researcher instead of giving an explanation from the theoretical standpoint of the researcher. "The phenomenological method should be descriptive because the phenomenological researcher wants to avoid any kind of premature analysis or explanatory constructs" (GIORGI, 1985, p. 47). The second characteristic, the reduction, refers to the idea of taking the meaning of any experience exactly as it appears or is presented in consciousness. Giorgi (1985, p .48) emphasizes this point when he affirms, "Whatever presents itself to consciousness should be taken precisely with the meaning with which it presents itself, and one should refrain from affirming that it is what it presents itself to be." The third characteristic is the search for essences, in which psychologists look for the invariant and unchangeable characteristics of the particular phenomenon under study. Giorgi clarifies that psychology is very interested in both essences that are context related and meaning structures that are situated in specific situations (GIORGI, 1985). Finally, the fourth characteristic is the notion of intentionality, which refers to the intentional act by which every human being 
is related to the world and objects. The intentionality is placed in the human consciousness, which, in turn, means that consciousness is always consciousness of something.

Now, we can take a look of those steps Giorgi uses for doing a protocol analysis. However, before following these steps it is necessary to clarify that, the researcher has to read and reread the protocol in order to catch the sense of the whole of it, trying to understand the meaning of the experience in terms of the standpoint of the co-researcher, and not in terms of the researcher's theory about the topic under study. Then, the researcher has to follow the experience of the coresearcher looking at her/his intentionality, instead of putting herl/his own intentionality in the experience of the coresearcher. If the prolOcol does not offer sufficient, clear data about the topic under study, the researcher could interview the co-researcher in order to clarify the confused points. This first reading, which is called familiarization, should not lead the researcher 10 make an interpretation of the co-researcher' s experience. The only goal here is to understand the language of the describer in order to grasp a sense of the whole of the coresearcher's experience. Giorgi (1985, p. 11) comments, "The general sense grasped after the reading of the text is not interrogated nor made explicit in any way. Primarily, it serves as a ground for the next step".

Once the researcher has read the protocol and has a sense of the whole, she/he has to divide the protocol or description into what Giorgi calls Meaning U nits. "The task in this step is to discriminate the different units or blocks that express a self-contained meaning" (POLKINGHORNE, 1989, p. 53). It is appropriate to bear in mind that we have to look at and understand these units or blocks in terms of the whole meaning, as Sokolowski emphasizes. Giorgi comments that the units are divided by looking at the different key terms, aspects, attitudes or values that the co-researcher expresses in the description. In this way, the researcher has to be aware of the changes in topics and meanings in the description. When the whole text or description is divided into meaning units, the researcher can analyze each of them easily because she/he has now manageable units.

If we are aware of what Sokolowski says about pans and whole, we can understand that the idea is neither to divide the different meaning units according to the researcher's standpoint, nor to treat each of them as a separate whole, because in this way we would be losing the context in which every meaning unit is based. As a consequence, we would ignore the concrete meaning of the meaning units, we would be projecting our own 
explanations on to the experience of the co-researcher and we would also interpret each meaning unit from our own point of view. Polkinghorne (1989, p. 54) also affirms this when he says, "the divisions are to be those that naturally cohere in the text rather than those imposed by the expectations of a researcher' s theoretical position".

It could be said that the meaning units do not really exist in the text or protocol as such, with which Giorgi would agree. The discrimination of each meaning unit depends on the relationship between the researcher and the protocol, which, in turn, means that the perspective of the researcher has to do with the division of the meaning units. However, we should also clarify that the researcher is not going to give an explanation to these meaning units at this point; she/he is only going to divide the description into smaller and more manageable units or blocks with which she/he can do a more detailed analysis. It is very important to note that while the researcher is dividing the protocol into meaning units, she/he always has to bear in mind the sense of the whole of the coresearcher's description in order not to impose a meaning that is not expressed by the coresearcher. In other words, this means that the different meaning units are not arbitrarily imposed, but they are established according to the general meaning that the co-researcher expresses in the description. Here, as Sokolowski emphasizes, we can see the importance of comprehending parts from the context in which those parts are based. Giorgi also says that the constant effort to clarify the meaning units leads the researcher to self-correction.

The next step is the transformation of the meaning units into a more psychological language. Polkinghorne (1989, p. 54) shows "that this transformation originally consists of two steps". First, the researcher has to state in her/his own language, and as simply as possible, the meaning that dominates each meaning unit. This first transformation from the co-researcher's words to the researcher's words still retains the co-researcher's context in which her/his experience has occurred. Later, the researcher does interrogate each meaning unit in the light of the topic under study. As Polkinghorne (1989, p. 54) says, "The question of study is put to each meaning unit and its accompanying first transformation." Here, the researcher relates each meaning unit to the topic under study and rewrites the meaning of each meaning unit into a more psychological language".

Nowadays, researchers are doing only one transformation directly, which includes both steps. Some researchers believe that it is very easy to change the meaning of the original and natural meaning unit by dividing the transformation into two steps. Then, instead of dividing the transformation into two steps, researchers are integrating both of 
them into one step. Polkinghorne (1989) shows how Van Kaam and Colaizzi, for example, go directly from the natural meaning units to the search for the essential elements of the general experience under investigation, which contrasts with Giorgi's idea of retaining the situated context in which the phenomenon occurs while he is doing the transformation. In any case, what has to be very dear is that the transformation is not accomplished through abstract thinking, but by going through the concrete expressions and language that the coresearcher is describing in order to redescribe the meaning of the coresearcher's reality and naïve language into a more psychological language. This transformation goes from a naïve description, which is in first person singular language, to a psychological scientific language, which is in third person singular. Giorgi (VON ECKARTSBERG, 1998, p. 39) "explains this by saying that each unit is systematically interrogated for what it reveals about the topic under study in a concrete situation for a specific person (the co-researcher)".

It is important to note that in this third step Giorgi begins to use one of the most important concepts of Husserl's phenomenology, the imaginative variation. "The intent of the method is to arrive at the general category by going through the concrete expressions and not by abstraction or formalization, which are selective according to the criteria accepted" (GIORGI, 1985, p. 17). By using the imaginative variation, the researcher begins to both follow the concrete experience of the co-researcher and reflect about the different possibilities of the meaning of her/his experiences. He tries to reach \{he essential and unchangeable meaning of the co-researcher' s experience at the same time that she/he discards those meanings that are not essential for the coresearcher in her/his concrete experience and situation. Polkinghorne (1989, p. 55) synthesizes this very well:

\footnotetext{
Imaginative variation is a type of mental experimentation in which the researcher intentionally alters, through imagination, various aspects of the experience, either subtracting from or adding to the proposed transformation. The point of free variation is to imaginatively stretch the proposed transformation to the edges until it no longer describes the experience underlying the subject's naïve description. The use of these processes is to enable the researcher to produce meaning transformations on which there is consistent intersubjective agreement.
}

Generally speaking, the next step refers to the synthesis and integration of the insights made by the researcher about the transformed meaning units of each protocol in order to make a final consistent description of the psychological structure under study (GIORGI, 1985). However, this step has originally two levels. Giorgi (1985) talks about the situated structure (the specific description) and the general structure (the general 
description). The situated structure is focused on the concreteness of the situation in which the phenomenon takes place. This means that the researcher synthesizes the meaning units of each description or protocol in order to make a descriptive statement of the particular and specific characteristics of every subject. On the other hand, after completing those specific or situated descriptions of each protocol, the researcher makes a general structure of each of them, in which she/he tries to reach and show the most general and essential meaning of the phenomenon under study. This general structure or description is focused on attending the aspects of the protocol that transcend a specific situation in order to find a general or universal validity. Now, the researcher is not focused on the particulars of the specific situation of the protocol, as he/ she was in the situated or specific description, but he/ she is trying to make a general statement about the essential and invariant aspects of the co-researcher' s experience that are transsituational. Von Eckartsberg (1998, p. 42) clarifies this when he comments:

Giorgi brings in anorher important distinction and order into the methodology
by identifyingthe situated stTUcture and the general strucrure. He works with
individual experiencesand protocols until he reachesthe levelof articulation of
situated stmerure. Only then doeshe "universalize" or "essentialize, that is,
transcend the existentially situated specificity in favor of na
essentialtranssituational understanding.

Nowadays, some researchers think that this separation between the situated structure and the general structure is unclear in some points in practice. Then, instead of doing an artificial division between these two levels of synthesis, they prefer to make one synthesis, in which they integrate the insights achieved into one coherent and consistente description. However, what it is clear is that this last synthesis has to answer to two questions in a very descriptive way: What is the essential structure of the phenomenon or experience? And how does that phenomenon or experience take place?

Finally, one last step is required: once the researcher has made a general description of the phenomenon under study, she/he has to do a final and single general analysis, in which she/he integrates and synthesizes the t:ransformed meaning units from a11the protocols of the study in order to describe what all the descriptions have in common. Polkinghorne (1989, p. 55) comments, "For this final step, the term situated can be dropped if a11of the subjects can be subsumed under one typology". The researchers, then, try to universalize the findings of the study by focusing on the essential aspects and characteristics of the studied phenomenon. It is important to note that in this step it is very important to bear in mind t:he intentionality and the sense of the whole of the co- 
researchers' experiences, if we want to find a coherent and final identification of the essences of the phenomenon.

After doing this, the researcher should present her/his findings or results in public. The researcher has to be sure of providing the descriptions, the analysis of meaning units and the data-analysis. It could also be pertinent to say that Giorgi does not like to use any quantification of his data nor include statistical percentages as Van Kaam does.

\section{References}

GIORGI, A. (Ed.). Phenomenology and psychological research. Pittsburgh: Duquesne University Press, 1985.

SOKOLOWSKI, R. Introduction to phenomenology. New York: Cambridge University Press, 2000.

MCCALL, R. Phenomenological Psychology. Madison, Wisconsin: The University of Wisconsin Press, 1983.

POLKINGHORNE, D.E. Phenomenological research methods. In: VALLE, R.S.; HALLING, S. (Eds.). Existentialphenomemological perspectives in psychology. New York: Plenum Press, 1989. p. 41-60.

VON ECKARTSBERG, R. Introducing Existential-Phenomenological Psychology. In: VALLE, R. (Ed.). Phenomenological inquiry in psychology: Existential and Transpersonal dimensions. New York: Plenum Press, 1998. p. 3-20.

VON ECKARTSBERG, R. (1998). Existential-Phenomenological Research. In: VALLE, R. Valle. (Ed.). Phenomenological inquiry in psychology: Existential and Transpersonal dimensions. New York: Plenum Press, 1998. p. 21-61.

Recebido em: 04 de fevereiro de 2018.

Aceito em: 10 de julho 2018 . 